\title{
PENDEKATAN SERVICE ORIENTED ARCHITECTURE (SOA) UNTUK MERESPON PERUBAHAN USER REQUIREMENT APLIKASI E-GOVERNMENT
}

\author{
Ahmad Nurul Fajar ${ }^{1}$, Imam Marzuki Shofi ${ }^{2}$ \\ ${ }^{1}$ Master of Information System Department, Bina Nusantara University Jakarta, Indonesia \\ ${ }^{2}$ Informatics Engineering Department, UIN Syarif Hidayatullah Jakarta, Indonesia \\ 1afajar@binus.edu, ${ }^{2}$ imam@uinjkt.ac.id
}

\begin{abstract}
ABSTRAK
Pendefinisian user requirement yang tidak komprehensif kadangkala menyebabkan pengembangan sistem informasi menjadi lama, over budget dan tidak dapat beradaptasi dengan perubahan regulasi. Selain itu, adanya anggapan bahwa tidak adanya perubahan regulasi dalam memberikan layanan kepada masyarakat. Hal ini disebabkan karena menganggap kondisi environment selalu berjalan normal. Pada kenyataanya, pengembangan sistem informasi memerlukan perhatian khusus untuk antisipasi terhadap kondisi environment yang tidak dapat diprediksi perubahannya. Penelitian ini diharapkan dapat memberikan kontribusi dalam hal pengembangan sistem berbasis Service Oriented Analysis \& Design dengan pendekatan SOA untuk mengakomodir perubahan user requirement agar dapat dijadikan referensi untuk melakukan penelitian lanjutan.
\end{abstract}

Kata kunci: SOA, User Requirement, Aplikasi E-Government, Perubahan

\begin{abstract}
User requirement defining is not as comprehensive as sometimes led to the development of information systems become old, over budget and can not adapt to the regulatory changes. Moreover, the notion that the absence of regulatory changes in providing services to the public. This is due to assume the condition of environment is always running normally. In fact, the development of information systems require special attention to the condition of the environment in anticipation of unpredictable changes. This research is expected to contribute in the development of systems based on Service Oriented Analysis \& Design with a SOA approach to accommodate changes in user requirements in order to be used as reference for conducting advanced research.
\end{abstract}

Keywords: SOA, User Requirements, E-Government Application, Changes 


\section{PENDAHULUAN}

Pendefinisian services yang tidak tepat kadangkala menyebabkan pengembangan sistem menjadi lama, over budget, dan tidak dapat beradaptasi dengan perubahan lingkungan sistem. Adanya anggapan bahwa tidak adanya perubahan user requirement disebabkan karena menganggap kondisi lingkungan pemerintahan selalu berjalan normal tanpa perubahan. Pada kenyataanya, pengembangan sistem memerlukan cara untuk melakukan antisipasi terhadap kondisi lingkungan sistem yang tidak dapat diprediksi perubahannya.

SOA (Service Oriented Architecture) muncul dengan menawarkan adaptif dan reaktif terhadap lingkungan serta menawarkan solusi atas kompleksitas proses bisnis, keberagaman sistem dan teknologi [1]. Sesungguhnya apa yang dijanjikan oleh SOA tidak hanya terbatas pada penghematan biaya dan tenaga dari upaya pembangunan aplikasi, namun pada akhirnya adalah terwujudnya suatu organisasi yang mampu dengan cepat mengadaptasi perubahan proses-proses bisnis di dalamnya agar mampu menjawab tuntutan pasar terkini [1][2].

Oleh sebab itu, fenomena pendekatan SOA dalam merespon perubahan user requirement masih memiliki peluang untuk dikaji lebih lanjut. Hal ini menjadi peluang pengkajian yang menarik karena permasalahan serius dalam pengembangan sistem adalah pemahaman mengenai urgensi suatu requirement. Requirement merepresentasikan spesifikasi yang lengkap yang harus dapat diturunkan dari prasyarat yang abstrak. Di sisi lain, hal ini merupakan hal yang sulit untuk bisa menentukan atau menjustifikasi requirement yang lengkap dan akurat sejalan dengan kepentingan bisnis.

\section{TINJAUAN PUSTAKA}

\subsection{SOC (Service oriented computing)}

Service computing adalah bidang riset baru yang berangkat dari bidang traditional computing yang tidak hanya terdiri dari permasalahan arsitektur, programming, deployment, dan permasalah rekayasa lainnya. Tetapi juga termasuk permasalahanpermasalahan manajemen seperti business component modeling, business process design, dan service delivery. Paulo mendefinisikan agility sebagai kemampuan dari organisasi untuk merasakan perubahan lingkungan dan meresponnya secara efektif dan efisien. Agility sudah digunakan pada filosofi manufacturing baru oleh perusahaan dalam berkompetisi lingkungan yang tidak jelas dan tidak dapat diprediksi [1].

Agility membutuhkan sumber daya manusia yang fleksibel, sistem yang fleksibel, organisasi dan hubungan dengan luar didefinisikan sebagai bidang baru yang bertujuan untuk menyatukan teknologi dengan memahami proses bisnis dan organisasi dan untuk memahami bagaimana kapabilitas tersebut dapat diberikan secara efisen dan menguntungkan[1][2].

Pada Gambar 1 ini diperlihatkan relasi-relasi antara berbagai konsep yang ada pada services computing.

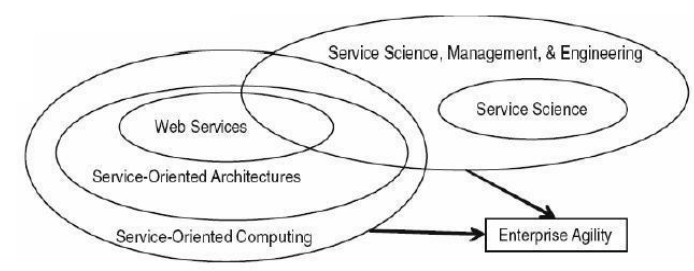

Gambar 1. Relasi SOC [1]

Dari Gambar 1 di atas dapat disimpulkan bahwa memang peranan SOA cukup menjanjikan untuk adaptif terhadap perubahan proses bisnis. Perusahaan yang selalu agile dalam menghadapi perubahan dan tekanan pasar bisnis untuk memenuhi kebutuhan customer memerlukan dukungan relasi konsep pada "services computing". Services computing membahas ilmu komputer tradisional hingga isu manajemen services.

\subsection{Requirements Engineering (RE)}

RE merupakan segala sesuatu (all about) yang berhubungan dengan kebutuhan untuk menemukan (discover), memahami (understand), memformulasikan (formulate), menganalisis (analyse), dan menyetujui (agree) pada masalah apa (what) yang harus diselesaikan, mengapa (why) masalah tersebut perlu diselesaikan, dan siapa (who) yang harus bertanggungjawab untuk menyelesaiakan masalah tersebut [37]. Why, what, dan who dikenal sebagai tiga dimensi dalam RE. 


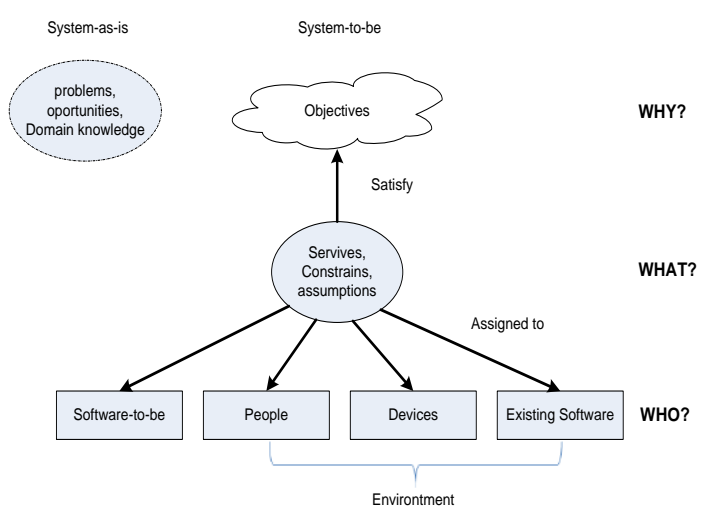

Gambar 2. Dimensi Requirement Engineering [3]

Dimensi why fokus pada alasan kontekstual terhadap usulan versi baru dari sistem yang secara eksplisit merupakan obyektif (objectives) yang harus dipenuhi berdasarkan keterbatasan-keterbatasan (limitations) dari system-as-is dan peluangpeluang eksploitasi dari system-as-is tersebut[3][4]. Dimensi what fokus pada layanan fungsional (functional services) system-to-be yang harus disediakan untuk memenuhi obyektif yang diidentifikasi pada dimensi why [3][4].

\subsection{Aplikasi E-Government}

Menurut Blue Print Sistem Aplikasi EGovernment, Depkomifo, 2004, pengelompokan aplikasi e-government di Indonesia ditunjukkan pada gambar dibawah ini:

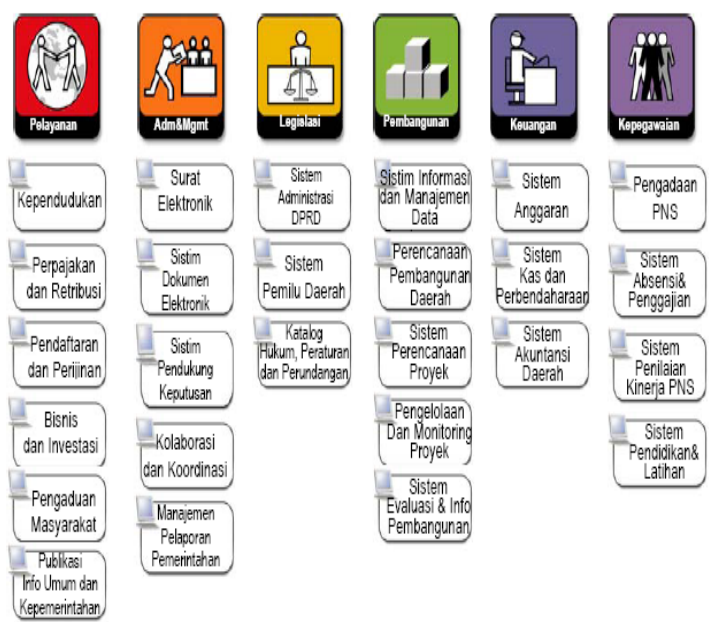

Gambar 3. Aplikasi Kepemerintahan di Indonesia [5]

Sistem aplikasi E-Government disusun berdasarkan pendekatan fungsional layanan dari sistem kepemerintahan yang harus diberikan oleh suatu pemerintah kepada masyarakatnya, dan urusan administrasi serta fungsi lain yang berhubungan dengan kelembagaan pemerintahan pusat, yang diperlukan guna terselenggaranya sistem kepemerintahan yang baik dan efisien.

Fungsi-fungsi kelembagaan, fungsi kepemerintahan, dan layanan kemudian dikelompokan dalam grup-grup blok fungsi. Setiap grup blok fungsi terdiri dari 1 atau lebih modul fungsi yang mencerminkan kelompok dari unit fungsi yang lebih kecil. Dengan demikian, modul adalah komponen dan merupakan bagian dari blok fungsi. Kelompok blok fungsi disusun dalam sebuah bagan fungsi yang selanjutnya disebut sebagai Kerangka Fungsional Sistem Kepemerintahan.

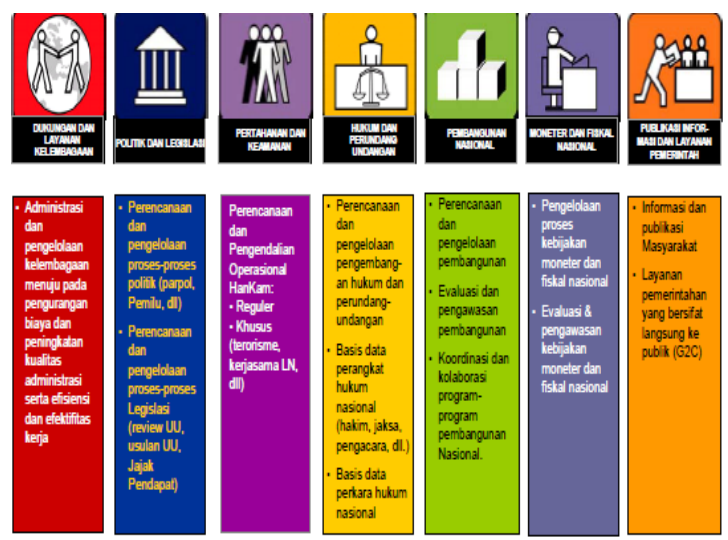

Gambar 4.21 Kerangka Fungsional Sistem Kepemerintahan [6]

\section{HASIL DAN PEMBAHASAN}

\subsection{Posisi Penelitian}

Perubahan yang terjadi dalam kondisi yang tidak diprediksi dapat terjadi pada domain bisnis maupun pada fungsi bisnis (functional area). Perubahan yang terjadi pada keduanya akan dapat menyebabkan pengaruh perubahan organisasi pada lingkup sistem enterprise, selanjutnya akan berpengaruh kepada perubahan kebutuhan informasi. Dengan adanya perubahan kebutuhan informasi, juga akan berpengaruh terhadap perubahan aplikasi dan infrastruktur yang ada. Pemetaan perubahan ini dapat dilihat pada gambar 4 di bawah ini: 


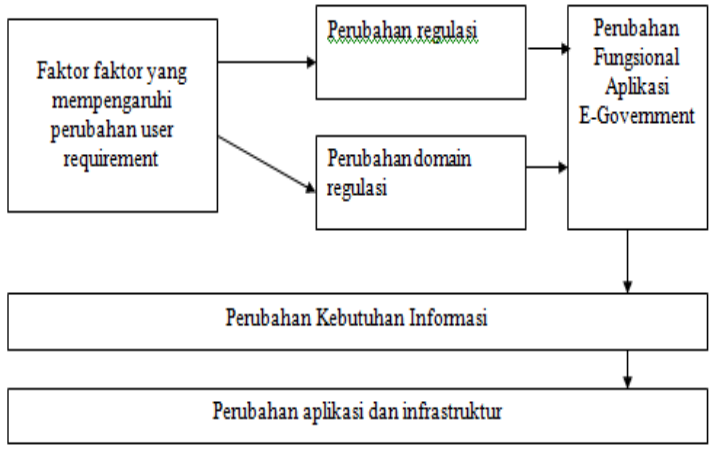

Gambar 4. Pemetaan perubahan regulasi

Beberapa penelitian yang sudah dilakukan mengenai SOA, posisi penelitian dan state of the art dapat ditunjukkan pada table 1. berikut ini:

Tabel 1. Posisi Penelitian \& State of The Art

\begin{tabular}{|c|l|}
\hline \multicolumn{1}{|c|}{$\begin{array}{l}\text { Kontribusi } \\
\text { Penelitian }\end{array}$} & \multicolumn{1}{c|}{ Author } \\
\hline $\begin{array}{l}\text { Dampak SOA terhadap } \\
\text { standarisasi proses bisnis }\end{array}$ & $\begin{array}{l}\text { Beimbom, Daniel et } \\
\text { all, } \\
2009\end{array}$ \\
\hline $\begin{array}{l}\text { SOA untuk industri di bidang } \\
\text { kesehatan }\end{array}$ & John Koisch et all, \\
\hline $\begin{array}{l}\text { Adopsi SOA untuk perusahaan } \\
\text { di negara Portugal }\end{array}$ & FLORENCE \\
\hline $\begin{array}{l}\text { SOA untuk kolaborasi riset dan } \\
\text { pendidikan doktor di Perguruan } \\
\text { Tinggi }\end{array}$ & Stefan klink et all, \\
\hline $\begin{array}{c}\text { Pendekatan Service Oriented } \\
\text { Architecture (SOA) Untuk } \\
\text { Merespon Perubahan User } \\
\text { Requirement Aplikasi } \\
\text { E-Government }\end{array}$ & \\
\hline
\end{tabular}

\subsection{Rekomendasi Arsitektur Sistem EGS (Enterprise Government System)}

Pengembangan sistem informasi yang dapat merespon perubahan user requirement pada aplikasi E-government dapat menggunakan paradigma pengembangan sistem berbasis services, yang biasa disebut SOAD (Service Oriented Analysis \& Design)[7]. Implentasi SOAD dapat diakomodir dengan pendekatan SOA (Service Oriented Architecture). Sistem dibangun berbasis web. Sistem yang dibangun berupa portal yang menyediakan multi aplikasi yang dapat digunakan oleh pemerintah pusat dan pemerintah daerah.

Portal juga menyediakan multi fitur dan use case yang generic dan spesifik. Di dalam portal, ada komponen-komponen yang dapat dibagi bersama-sama dan ada juga komponen yang spesifik. Jika suatu daerah hendak mengembangkan aplikasi baru dengan suatu proses bisnis yang spesifik sesuai dengan Perda-nya, bisa reuse komponen yang eksisting dan menambah komponen baru yang spesifik. Tapi syaratnya, komponen yang direuse juga harus di desain fleksibel sehingga memungkinkan beberapa prosesnya override.

Rekomendasi Arsitektur EGS (Enterprise Government System) dijelaskan pada gambar 5 dibawah ini:

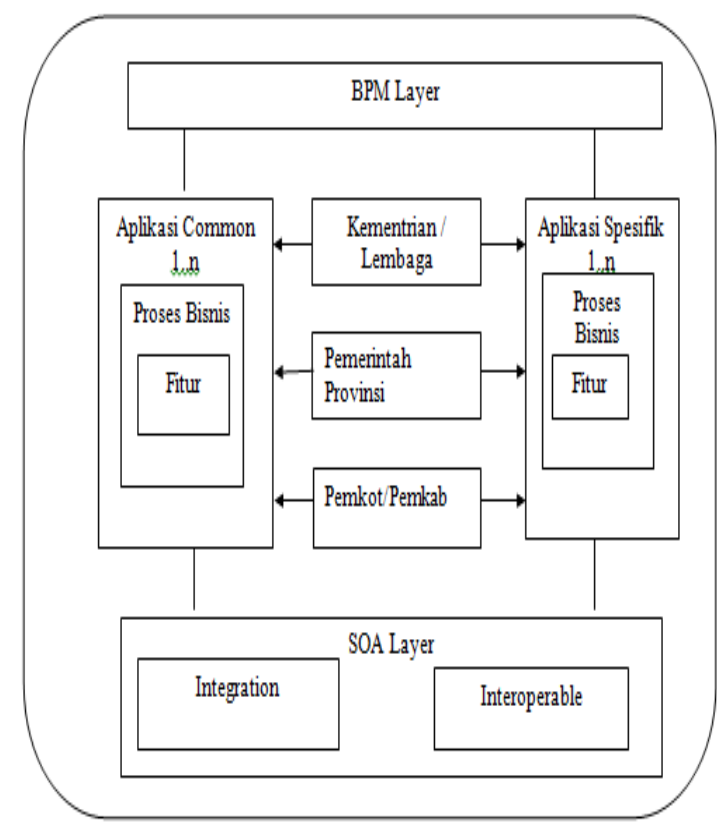

\section{Gambar 5. EGS (Enterprise Government System)}

Pada gambar 5 diatas, menunjukkan integrasi antara BPM dan SOA yang direpresentasikan oleh layer BPM dan Layer SOA. Integrasi ini dapat mengakomodir kementrian dan lembaga yang masing-masing memiliki aplikasi untuk menjalankan proses bisnis di pemerintahan. 


\subsection{Studi Kasus : Modul Perpajakan}

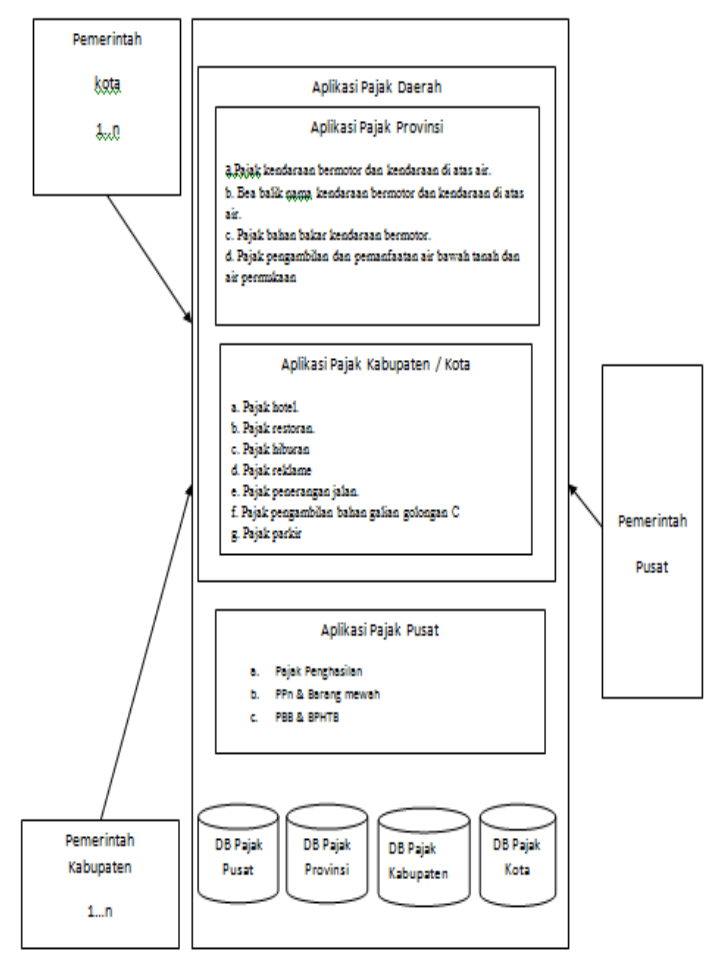

Gambar 6. Studi Kasus Modul Perpajakan

\section{KESIMPULAN}

Pengembangan sistem informasi yang dapat merespon perubahan user requirement pada aplikasi E-government dapat menggunakan paradigma pengembangan sistem berbasis services, yang biasa disebut SOAD (Service Oriented Analysis \& Design) dengan pendekatan SOA (Service Oriented Architecture). Sistem dibangun berbasis web. Sistem yang dibangun berupa portal yang menyediakan multi aplikasi yang dapat digunakan oleh pemerintah pusat dan pemerintah daerah. Portal juga menyediakan multi fitur dan use case yang generic dan spesifik. Di dalam portal, ada komponenkomponen yang dapat dishare bersama sama dan ada juga komponen yang spesifik. Jika suatu daerah hendak mengembangkan aplikasi baru dengan suatu proses bisnis yang spesifik sesuai dengan Perdanya, bisa reuse komponen yang eksisting dan menambah komponen baru yang spesifik. Tapi syaratnya, komponen yang di-reuse juga harus di desain fleksibel sehingga memungkinkan beberapa prosesnya di-over-ride.

Implikasi penelitian ini adalah dapat memberikan panduan kepada pengembang sistem informasi untuk menyediakan sistem yang fleksibel dan adaptif terhadap perubahan user requirement. Kemudian, paradigma pengembangan sistem dengan berbasis services dapat dijadikan panduan untuk mewujudkan sistem yang adaptif terhadap perubahan user requirement.

Rekomendasi penelitian ini adalah agar dapat dilanjutkan untuk mengembangkan sistem berbasis services (Service Oriented Analysis and Design) dalam lingkup Enterprise Indonesia Government System. Namun, dalam penerapannya perlu memperhatikan fase requirement engineering dengan menerapkan Goal Oriented Requirement Engineering (GORE).

\section{DAFTAR PUSTAKA}

[1]. Michael P.Papazoglou, Paolo Traverso,Schahram, Frank (2006), "Service Oriented Computing Research Roadmap".

[2]. Antoine Lonjon MEGA (2005), "Challenges and Methods for the Implementation of Service Oriented Architecture : An Update Enterprise Architecture", BP Trends.

[3]. Van Lamsweerde, A., "Requirements Engineering, From System Goal to UML Models to Software Specification", John Wiley \& Sons Ltd, 2009.

[4]. B. Nuseibeh, S. Easterbrook. "Requirements Engineering: A Roadmap". Proc. Conference on the Future of Software Engineering.Limerick, Ireland, June 2000.

[5] Departemen Komunikasi dan Informatika , 2004, Blue Print Sistem Aplikasi EGovernment.

[6]. Departemen Komunikasi dan Informatika, 2006, Rancangan Blue Print E-Government.

[7]. Erl, T. 2005. Service Oriented Architecture: Concepts, Technology, and Design . Prentice Hall. 
